\title{
Roberto C. Simonsen e sua Obra
}

Roberto Cochrane Simonsen, ou Roberto C. Simonsen, como gostava de assinar, nasceu em Santos a 18 de fevereiro de 1889 e morreu no Rio de Janeiro, a 25 de maio de 1948. Filho de Sidney Martin Simonsen e Robertina Cochrane Simonsen, estudou no Colégio Tarquínio Silva (Santos) e colégio AngloBrasileiro (São Paulo), ingressando com 15 anos na Escola Politécnica de São Paulo.

Em 1910 forma-se engenheiro, indo trabalhar na Sothern Brazilian Railway e, depois, na Prefeitura de Santos. Em 1912 funda, com diversos companheiros, a Companhia Construtora de Santos (1912-1940), firma pioneira, cujos planejamentos urbanísticos deram feição moderna à cidade; numa época em que as construções eram feitas empiricamente pelos empreiteiros, a companhia executa projetos técnicos e arquitetônicos modernos; pavimenta parte da cidade e constrói armazéns e bancos, a Bôlsa de Café e a Associação Comercial, a Base da Aviação Naval, etc. Para cuidar especificamente da construção de casas o pioneirismo na capital paulista cabe aos inglêses, com a
Companhia City - Simonsen instala a Companhia Santista de Habitações Econômicas, que funda o bairro modelar de Vila Belmiro e um outro, de mais luxo, próximo ao Hotel Parque Balneário; no entanto, a construção de casas populares fica paralisada devido à crise de 1920.

Sua atividade como engenheiro civil atinge 0 ápice com a construção de quartéis, simultâneamente em 26 cidades $e$ nove estados. A encomenda foi de Pandiá Calógeras, Ministro da Guerra do govêrno de Epitácio Pessoa. As obras se iniciaram em 1920 (ver pormenores e informações em A construção dos quartéis para 0 Exército).

Também as atividades industriais o preocupam: em 1912 já fundara a Companhia Frigorífica de Santos (que dura até 1919) e, logo depois torna-se presidente da Companhia Frigorífica e Pastoril de Barretos (1919-24). É eleito diretor da Companhia Nacional de Artefatos de

* Professor do Departamento de Ciências Sociais da Escola de Administração de Emprêsas de Săo Paulo, da Fundação Getúlio Vargas. 
Cobre (1926-28), presidente da Companhia Nacional de Borracha (1926-27) e presidente do Sindicato Nacional de Combustiveis Líquidos (1923-28). Nessa época lidera a cisão da Associação Comercial e torna-se um dos fundadores do Centro das Indústrias do Estado de São Paulo (1928). Enquanto se dedica às atividades de construtor e industrial, outra tarefa o absorve, a do comércio do café. Prosseguindo a tradição de família - como no caso de seu parente, 0 engenheiro Inácio Wallace da Gama Cochrane - torna-se sócio da Casa Comissária Murray Simonsen Co., que durante 0 govêrno de Washington Luís representou os banqueiros inglêses Lazard Brothers, um dos financiadores do Instituto Paulista de Defesa do Café.

A sua ação se multiplica após a revolução de 1930: participa ativamente da mobilização industrial paulista durante a revolta de 1932; é eleito deputado pela Assembléia Nacional Constituinte (1934) e exerce o cargo até 1937. É presidente do Instituto de Engenharia de São Paulo (1933-34) e da Confederação Industrial do Brasil (1935-36). Sua ação diretora alia-se às novas iniciativas, como a fundação da Cerâmica São Caetano e da Companhia Imobiliária Nacional.

Durante o Estado Nôvo pertence ao Conselho de Expansão Econômica do Estado de São Paulo (1938-41), ao Conselho Nacional de Política Industrial e Comercial, ao Centro das Indústrias do Estado de

São Paulo, etc.

Após 1945, combate tenazmente o comunismo, idealizando as criaçōes do SENAI e SESI, órgãos ligados à Federação das Indústrias e destinados a meIhorarem as condições técnicas e humanas dos operários. Como senador - eleito em 1946 - apóia a cassação dos mandatos comunistas em 1947.

Sua atividade prática sempre foi acompanhada de reflexões teóricas. Grosso modo poderíamos dividir a sua obra em dois momentos básicos: antes e depois de 1930. A divisão se justifica porque no primeiro período seus trabalhos se relacionam mais com problemas específicos de sua profissão: a Prefeitura de Santos, o calçamento em São Paulo, a carne e pastagens no Brasil, missão à Inglaterra, a função dos homens de negócio, etc. Algumas questões teóricas já aparecem expostas em 0 trabalho moderno ou no discurso de inauguração do Centro das Indústrias do Estado de São Paulo, mas o que predomina são problemas imediatistas, preâmbulo à obra que irá realizar na segunda fase.

E a partir de 1930 que teremos reflexões mais profundas e completas, nas quais o conhecimento prático - ou imediatista - alia-se ao conhecimento histórico. A série de ensaios publicados mostra a curiosidade múltipla de Simonsen pelos problemas brasileiros, encarados de maneira global e não mais particular.

Estes aspectos aparecem nas diversas partes de seus livros. Não podemos esquecer que esta é a razão maior do interêsse de sua obra. É que, para Simonsen, conhecimento histórico é também análise dos fatôres geográficos e demográficos, econômicos e financeiros, de problemas sociais, etc., fato que torna sua contribuição grandemente superior à da maior parte dos nossos teóricos anteriores do pensamento industrial. $E$ é esta soma que marca sua contribuição, tornando-a fundamental e permanente.

As obras de Antônio Felício dos Santos, Amaro Cavalcanti, Américo Werneck, Jorge Street, etc. são essenciais para o conhecimento da problemática industrial entre 1880 e 1930. Elas levantam questões cruciais do nascente industrialismo brasileiro, como as de mercado interno, tarifas, câmbio, imperialismo, etc. A maior parte desta contribuição limitase, porém, à análise de rei- vindicações momentâneas, dentro de um caráter imediatista. Apesar de básicas, sua compreensão se limita ao tempo. A restrição ou limitação tornase, então, o traço característico do que poderíamos chamar de primeiro momento ou fase do pensamento industrial brasileiro.

Roberto Simonsen representa um momento diferente. E verdade que êle tem atrás de si um número considerável de pensadores, que 0 antecedem e o ajudam a questionar o problema industrial nascente.

Mas, devido à sua visão mais larga, o que o preocupa é a resolução não só dos problemas cotidianos da indústria, mas a superação de obstáculos inerentes à nossa industrialização. A racionalidade do trabalho e a idéia do planejamento da economia são os dois pontoschaves de sua contribuição, elementos fundamentais de seu pensamento, que fogem totalmente à tradição da fase anterior. Estes elementos marcarão intelectualmente a presença da nova elite industrial brasileira, da qual Simonsen é o maior expoente.

E verdade que a racionalização do trabalho é posta em prática durante sua gestão na Companhia Construtora de Santos; e que o planejamento da economia só se realiza no Estado Nôvo. No entanto, estas medidas são preconizadas por Simonsen desde 1930, e concretizam-se na fundação do IDORT e na tentativa de ampliação das atividades do Instituto de Pesquisas Tecnológicas. Por outro lado, as dificuldades da II Guerra Mundial levam o govêrno a intensificar sua política de intervenção na economia Instituto Brasileiro de Café, Instituto do Açúcar e do Álcool, Volta Redonda - criando, afinal, a Comissão de Planejamento Econômico, Conselho Nacional de Política Industrial e Comercial, etc. Assim, a teoria e a prática do planejamento e a racionalização encontram um modus vivendi, resultado da 
colaboração entre o particular e o governamental, para a solução de nosso impasse econômico.

Preocupado com a difusão de suas idéias, Roberto $\mathrm{C}$. Simonsen editou êle próprio tôda a sua obra. Com exceção da História econômica do Brasil, sua produção teve divulgação restrita, o que limita o seu conhecimento. Seus escritos tratam de diversos aspectos da economia, num aprofundamento de temas determinados.

Apesar de seu didatismo, o que não se pode negar é o fato de que seus estudos são mais completos do que a maioria dos trabalhos contemporâneos. Além de uma boa biblioteca geral, que o mostra familiarizado com a história, Simonsen utiliza-se de fontes primárias, numa descrição e aprofundamento do processo de produção agrícola e comercial, que o dota de uma visão "marxista" da história.

Demonstra o mesmo cuidado quando se trata da indústria, procurando sempre encaminhar os estudos para o conhecimento dos seus fatôres determinantes. É verdade que êle é um determinista geográfico, posição inicial que é esquemática e fàcilmente criticável. Mas a noção que dá dos diversos fatôres de desenvolvimento da indústria - imigração, mercado interno, eletricidade, política tarifária, inflação, acúmulo de capitais agrícolas - e da importância da cultura do café, como fator primeiro e determinante para o processo industrial, torna-o um pioneiro.

A falta de trabalhos posteriores sôbre a matéria leva-nos, ainda, a utilizar o seu esquema, que é aproveitado por quase todos os que fazem estudos a respeito de história industrial e econômica.

Se o historiador é objetivo, o industrial é nacionalista e consciente dos problemas de sua época. Nacionalismo não significa aqui xenofobia, mas to- mada de posição consciente a favor do progresso de sua classe e dos interêsses brasileiros. Desde os seus primeiros escritos, êle rebate as afirmações de que a indústria é artificial e que importa a maior parte de sua matéria-prima do estrangeiro, o que oneraria o seu preço; que existiriam conflitos permanentes entre a agricultura e indústria, etc. Por sua vez, aplaude as medidas ou situações favoráveis ao desenvolvimento industrial, como a política do câmbio baixo (câmbio vil, de Washington Luís), ou o protecionismo governamental, etc.

Clara é também a sua posição em relação ao imperialismo. Simonsen não é contra os capitais externos, mas compreende que suas aplicações devem ser feitas em benefício de ambos os participantes. Num momento em que a influência econômica americana substitui a européia, êle define claramente o perigo da permanência do processo espoliativo capitalista, preconizando novas fórmulas: "ora, a substituição dos artigos que habitualmente importávamos da Europa, por outros, de procedência norteamericana, aumenta as cifras do comércio exportador dêsse país, favorece, eventualmente, o progresso econômico de alguns de seus ramos industriais, mas não concorre para o fortalecimento da economia do Brasil. Os acôrdos de comércio ajustados sob essa inspiração não oferecem a segurança de uma larga, permanente e recíproca interpenetração de atividades produtoras e de consumo, segurança que deveria constituir o seu principal objetivo (...). Só existe um meio seguro de aumentar, em caráter estável e de forma absoluta, as trocas de produtos entre as nossas nações, com proveito real para ambas e com benefícios reflexos sôbre o comércio internacional em geral. E o que promana do fortalecimento econômico dos nossos países, pela maior utilização e inteligente desenvolvimento de seus recursos, de tal sorte que as correntes de negócios cria- das resultem da formação de novas riquezas e não de um simples fogo de substituição de mercados. (O grifo é do autor) (...) Do que precisamos, precipuamente, é de procurar obter a cooperação econômica, de forma a elevar, substancialmente, as rendas nacionais dos dois países." 1

A tecnologia e a planificação aparecem-lhe como elementos de afirmação para um nôvo surto industrial, contrapondo-se a tôdas as vicissitudes existentes. Esta consciência técnica manifesta-se já no início de sua carreira. E, ao contrário dos teóricos do pensamento industrial da primeira fase, êle sublinha não só os limites do seu objetivo, mas indica o caminho da sobrevivência industrial. A racionalidade do trabalho é corolário da racionalidade da economia ou da racionalidade tecnológica. Porém, a sua visão não é restrita, o que o leva a sublinhar nitidamente "que é baixo o nivel de vida do brasileiro e pouco elevada a renda nacional; que o nosso aparelhamento econômico e, sobretudo, o nosso equipamento industrial é, em grande parte, insuficiente e antiquado; que a planificação representa uma técnica econômica de melhoria da produção; que, no caso brasileiro, a plaficação traduzirá, ainda, a recuperação do tempo perdido; que a planificação econômica nacional deve abranger o trato dos problemas industriais, agrícolas e comerciais, bem como o dos sociais e econômicos, de ordem geral; que a observação do processo econômico internacional, no período anterior à guerra, demonstrou, dentro do ritmo normal da evolução social e econômica, não ser possivel para a maioria das nações, empobrecidas por falta de recursos naturais, baixa produtividade das populações, ambiente geográfico e outras causas, alcançar, ràpidamente, um nível de renda nacional que Ihes permita assegurar um padrão de vida conveniente". ${ }^{2}$ 1 Simonsen, R. C. Elos da indústria. p. 14-19.

2 Congresso Brasileiro da indústria. v. 1 , p. 182-83. 
A perspectiva histórica também é fundamental para seus estudos agrícolas. O que êle acentua é a idéia de que, sem uma visão passada, é impossível superar os entraves presentes. Daí o seu interêsse pelos problemas gerais agrícolas, que transparece vivamente na História econômica do Brasil (1500-1820). Em grande parte pioneira, sua análise abrange a economia da época e descreve o seu processo dialético.

O mesmo se dá nos ensaios sôbre o café, algodão, etc. 0 historiador aparece identificado com o geógrafo, o pesquisador social, etc. No ensaio Aspectos da história econômica do café, as condições naturais, a mão-deobra, o problema do custo, a questão do transporte, as vicissitudes do valor, a questão portuária e das condições do mercado externo surgem constantemente como elementos intrìnsecamente ligados. $E$ esta visão que permitirá que êle levante questões ou aplauda medidas. No entanto, quando persiste a crise cafeeira após 1930, seu realismo traduz-se na preconização de medidas drásticas, quando pede o término da política da queima do café, pois o seu custo implica em grandes gastos e desvio de mão-de-obra necessária a outras atividades. A mesma política é seguida quando afirma a necessidade de um sistema cadrastal, que permita o levantamento da realidade cafeeira entre nós.

Os textos mais incisivos e clarividentes aparecem na parte que denominamos Questóes econômicas. Na sua análise, surge claramente 0 problema da limitação do nosso capitalismo e de sua vassalagem ao capitalismo internacional. 0 autor faz análise realista do problema, mas sua posição é sòmente de inconformismo e não de combate. A limitação é intrínseca à nossa burguesia, que sempre se identificou com os capitais externos e nunca se opôs às formas de sua aplicação ou ao seu contrôle externo sôbre nossa produção agrícola e extrativa.

E nos textos escritos durante a II Guerra Mundial, momento crucial de um impasse econômi$\mathrm{co}$, que encontramos melhor desenvolvido o seu pensamento. Simonsen, em 1943, mostra que o ritmo do progresso brasileiro, num aparente momento de prosperidade, é ilusório, pois não dispomos de "combustíveis, de indústrias básicas, de máquinas, capitais e técnicos em número suficiente para levarmos a mobilização industrial a um nível capaz de assegurar um volume de produção, na mesma escala da inglêsas ou norte-americana". Por sua vez, afirma lùcidamente que o "saldo de dívidas estrangeiras de que dispomos representa a diferença dos valôres exportados, em relação ao que pudemos importar, o que, aliás, não correspondeu às nossas necessidades efetivas. No terreno da relatividade nos empobrecemos, de fato,

comparativamente com os indices de enriquecimento das potências democráticas"

(Alguns aspectos da política econômica mais conveniente ao Brasil no período do apósguerra). A conclusão é de que houve, simplesmente, diminuição do volume de materiais e matérias-primas exportadas e aumento de exportação de alguns artigos básicos aos países em conflagração, e acompanhados de um aumento de seus preços.

Mais contundente é a posição exposta num de seus últimos trabalhos. Em Direito internacional social, sublinha que "não quisemos ou não pudemos compreender, até hoje, que tratados de reciprocidade, baseados na cláusula de nação mais favorecida, contendo condições jurídicas e teòricamente iguais para ambas as partes contratantes, acarretam, de fato, sob o ponto de vista econômico, uma progressiva vassalagem da nação menos aparelhada à mais poderosa"; "quando se realizam tratados de comércio entre uma nação fortemente industrializada e outra em que predominam, como artigo de exportação, os chamados produtos coloniais, promove-se, de fato, a troca de produtos fracamente remunerados, por outros altamente recompensados. Mesmo que se equilibrem, em valor monetário, os balanços de comércio e de pagamentos entre essas nações, o intercâmbio realizado favorece, sem dúvida, o país mais industrializado. Em verdade, tais tratados de comércio deveriam ser completados por entendimentos em que o país que coloca, em troca de produtos primários, artigos densamente remunerados se obrigasse a uma cooperação compensadora, de ordem técnica e econômica, ao exportador de produtos primários". "Podemos considerar que, na ordem internacional, há uma diferenciação hierárquica entre as nações, a qual corresponde à estrutura e ao papel desempenhado pela economia de cada uma delas nas relações internacionais".

Assim, seu pensamento sôbre o impasse da economia atual demonstra uma visão realista, mas uma solução utópica. Quando trata do problema social ou da relevância das camadas dirigentes brasileiras, sua posição é a de um tradicionalista. Num país de passado paternalista e autoritário, onde as classes dirigentes sempre foram pequena minoria, seria natural a permanência ou a transposição de seus ideais a fórmulas novas. Um exemplo característico é a maneira com que foi tratada a classe operária: no momento de sua ascensão - principalmente a partir do início do século - as classes dirigentes tentam sufocar suas reivindicações, adotam tênues medidas em seu benefício ou criam fórmulas "ideológicas" críticas sôbre os imigrantes e seus malefícios.

Este último aspecto tem sido totalmente neglicenciado, o que nos impede de ter uma visão mais crítica do pensamento das classes dirigentes. Não que faltem testemunhos ideológicos, pois os jornais e outros meios 
de informação reproduzem constantemente a opinião dos industriais e fazendeiros sôbre a "ingratidão" de uma classe (imigrantes), que se beneficia das nossas riquezas e oportunidades e, no entanto, levanta celeuma e questões sociais "extemporâneas" ao Brasil.

Simonsen é exemplo desta tendência. Para êle, os operários são "almas boas e simples" que vêm ao Brasil por "necessidades econômicas", ou pelo "sonho da fortuna", ou à procura da "liberdade que a Pátria recusava". Em compensação, pensam em têrmos de "limitação da produção e de ilimitação de salários". Porém, a epidemia da gripe espanhola (1918) propiciou um movimento de solidariedade entre as classes, que "deve sempre imperar entre os sêres humanos". Suas soluções paternalistas logo são contraditas pelos fatos, o que o leva, mais tarde, a aplaudir a luta contra a rebeldia operária, ser favorável à criação do Ministério do Trabalho, à formulação do salário mínimo e à tôda política trabalhista do Estado Nôvo. Após a redemocratização de 1945, Simonsen pensa em têrmos mais amplos e preconiza a ação conjunta do Estado e das classes patronais; na luta contra o comunismo e as reivindicações revolucionárias do operariado. Entretanto, se o instrumento tornou-se mais amplo, a fórmula conciliatória permanece: "não há questão social - habitação, alimentação, educação, saúde e outras - cuja solução exija mais do que apenas boa vontade e diligência por parte dos que respondem pela preservação do nosso patrimônio social e histórico". Em 1947 volta a insistir na política "em tôrno de rumos definidos, à procura de um ideal comum". E, na hora de preconizar o fechamento do Partido Comunista (1947), define democracia por "regime político emanado direta e livremente da vontade popular, orientando e solucionando problemas que decorrem das relações individuais e coletivas, com a necessária flexibilidade permissiva de uma segura evolução econômica e social do povo" (o grifo é nosso).

A idéia de democracia limitativa é própria de nossa formação elitista, apesar das transformações que a classe dirigente e oligarca brasileira vem sofrendo històricamente. Não se pode negar a grande contribuição de um Simonsen, quando divulga e adota formas racionais de trabalho (taylorismo, etc.), o ensino técnico e sociológico, etc. Porém, há um limite entre concessão e direitos. No entanto, as classes dirigentes sempre agiram em têrmos de concessão, como soluções políticas paliativas, 0 que as leva a encarar a desigualdade de classes, e até de raças, como situação natural. A permanência dêssses valôres de classes é que permite a Simonsen repetir, em 1940 num brado saudosista que não se cultive "a ilusão de uma possível igualdade social e material entre os homens. A hierarquia social, que se estabelece em função da capacidade dos valôres individuais nunca poderá desaparecer, em harmonia, aliás, com tudo quanto se observa na natureza".

A esdrúxula permanência de valôres do século XVIII é que nos permite entender melhor certas tentativas burguesas de afirmação intelectual. Quando um Júlio de Mesquita Filho ou um Roberto C. Simonsen falam da necessidade de instalar faculdades no Brasil, o que pretendem é instrumentalizar, no sentido moderno, a velha elite brasileira. Em 1925, com A crise nacional, Júlio de Mesquita anuncia seu intento. Oito anos depois, Simonsen diz que "a formação das elites deve pois constituir uma das preocupações primaciais das sociedades modernas. Qualquer instituição social, qualquer escola doutrinária que aspire a ser adotada, qualquer associação industrial ou comercial para colimar seus objetivos, tôdas necessitam e exigem, cada vez mais, elementos de elite na sua direção. Possuindo escolas superiores de incontestável valor, São Paulo precisa agora formar as suas elites, educadas nas ciências sociais e no conhecimento das verdadeiras condições em que evolui a nossa sociedade, como meio de mais fàcilmente se aparelhar à conveniente escolha de seus homens de govêrno." (Rumo à verdade).

Apesar de algumas limitações em seu pensamento, a obra de Roberto C. Simonsen permanece pelo seu valor e interêsse básico. E seus estudos são marco de uma época, em grande parte insuperados.

\section{REFERENCIAS \\ BIBLIOGRAFICAS:}

Obras de Roberto C. Simonsen (em ordem cronológica).

The meat \& cattle industry of Brazil: its importance to Anglo Brazilian Commerce. London, Industrial Publicity Service, 1919.

O trabalho moderno. São Paulo, Seção de obras do Estado, 1919.

Orientação industrial brasileira. (Discurso proferido na inauguração do Centro das Indústrias do Estado de São Paulo.) São Paulo, Escolas Profissionais do Liceu Coração de Jesus, 1928.

As crises no Brasil: outubro de 1930. São Paulo, São Paulo Editôra Ltda., s.d.

As finanças e a indústria. (Conferência realizada no Mackenzie College, em São Paulo, a 8 de abril de 1931.) São Paulo, São Paulo Editôra Ltda., 1931.

\section{A construção dos quartéis} para o Exército. São Paulo, 1931.

A margem da profissão. São Paulo, São Paulo Editôra Ltda., 1932.

Rumo à verdade. (Discurso oficial na fundação da Escola Livre de Sociologia e Política de São Paulo, a 27 de maio de 1933.) São Paulo, São Paulo Editôra Ltda., 1933. 
Ordem econômica, padrão de vida e algumas realidades brasileiras. São Paulo, São Paulo Editôra Ltda., 1934.

Aspectos da política econômica nacional. (Discurso pronunciado na Câmara Federal dos Deputados, em 11 de setembro de 1935.) São Paulo, Revista dos Tribunaes, 1935.

História econômica do Brasil 1500-1820). 3. ed. São Paulo, Nacional, 1957. (Biblioteca Pedagógica Brasileira-Brasiliana, grande formato, v. 10.)

Possibilidades da expansão industrial brasileira. Parecer apresentado ao Conselho Federal de Comércio Exterior. Rio de Janeiro, Jornal do Commercio, 1937.

A indústria em face da economia nacional. São Paulo, Revista dos Tribunaes, 1937.

Saudação ao menor que trabaIha: proferida ao microfone da P.R.B.6 Rádio Cruzeiro do Sul, a 17 de outubro de 1939.

A evolução industrial do Brasil. Memorandum preparado a convite do Conselho Federal de Comércio Exterior, especialmente para a Missão Universitária Norte-americana, em visita ao Brasil. São Paulo, Revista dos Tribunaes, 1939.

Aspectos da história econômica do café. Separata da Revista do Arquivo, São Paulo, n. 65, 1940.

Niveis de vida e a economia nacional. São Paulo, 1940.

As indústrias e as pesquisas tecnológicas. Discurso profeferido na solenidade inaugural da IV Reunião da Associação de Normas Técnicas realizada a 13 de outubro de 1941, na sede do Instituto de Engenharia de São Paulo. São Paulo, FIESP, 1941.

Ensaios sociais, políticos e econômicos. São Paulo, FIESP, 1943.
Elos da indústria. Quatro discursos pronunciados em junho de 1944. São Paulo, FIESP, 1944.

A planificação da economia brasileira. Parecer apresentados ao Conselho Nacional de Política Industrial e Comercial, em 16 de agôsto de 1944. São Paulo, São Paulo Editôra S.A., 1952.

A engenharia e a indústria. São Paulo, 1945.

Roosevelt. Discurso pronunciado no Teatro Municipal, a 14-4-45, nas comemorações do dia Pan-americano. São Paulo, Edigraf, 1945.

A indústria e seus problemas econômicos e sociais. Discursos pronunciados por ocasião da solenidade de instalação da 5. a Feira Nacional da Indústria. São Paulo, FIESP, 1945.

O problema social no Brasil. Discurso pronunciado a 25 de julho de 1946, em São Paulo, na instalação do $1 .{ }^{\circ}$ Conselho Consultivo do SESI. São Paulo, 1947.

As atividades do Serviço Social da Indústria no Estado de São Paulo. Relatório apresentado ao Conselho Regional do SESI, em 2 de maio de 1947. São Paulo, SESI, 1947.

As classes produtoras do Brasil e o Partido Comunista.

Discurso proferido na sessão do dia 2 de junho de 1947, no Senado Federal. Rio de Janeiro, Imprensa Nacional, 1947.

Recepção de Roberto Simonsen na Academia Brasileira de Letras, em outubro de 1946: discurso do recipiendário e resposta de José Carlos de Macedo Soares. São Paulo, 1947.

Direito internacional social. Rio de Janeiro, 11 de maio de 1948.

O Plano Marshall e um nôvo critério nas relações internacionais. Conferência pronunciada no Clube Militar, no Rio de Janeiro, a 28 de abril de 1948. Rio de Janeiro, 1949.
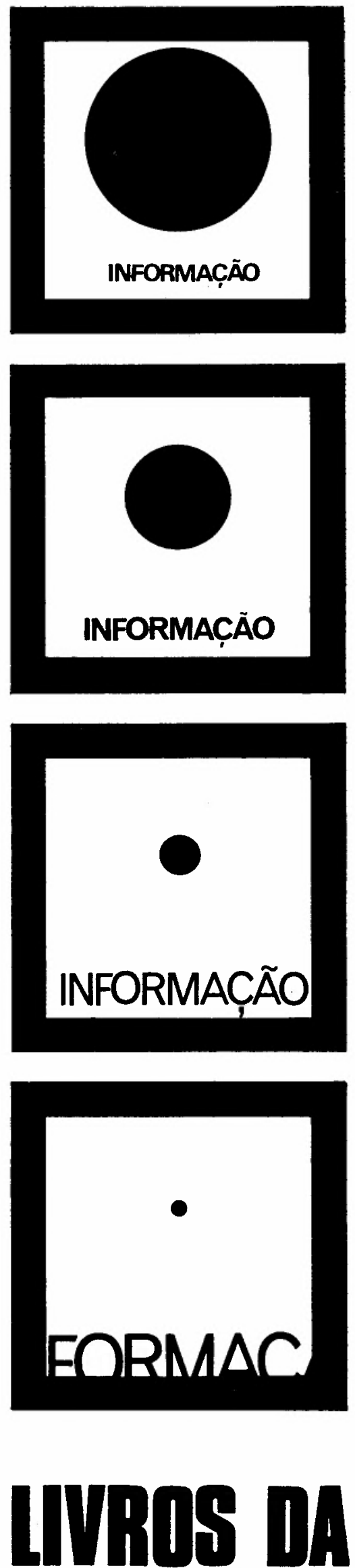

Fundacão Gatưlio Vargas 